\title{
PEDIATRIC SHORT COMMUNICATION Sexual dimorphism in relation to adipose tissue and intrahepatocellular lipid deposition in early infancy
}

\author{
C Gale ${ }^{1}$, KM Logan ${ }^{1}$, S Jeffries ${ }^{1}$, JRC Parkinson ${ }^{1}$, S Santhakumaran ${ }^{1}$, S Uthaya ${ }^{1}$, G Durighel ${ }^{2}$, A Alavi $^{3}$, EL Thomas $^{4}$, JD Bell $^{4}$ and N Modi $^{1}$
}

Sexual dimorphism in adiposity is well described in adults, but the age at which differences first manifest is uncertain. Using a prospective cohort, we describe longitudinal changes in directly measured adiposity and intrahepatocellular lipid (IHCL) in relation to sex in healthy term infants. At median ages of 13 and 63 days, infants underwent quantification of adipose tissue depots by whole-body magnetic resonance imaging and measurement of IHCL by in vivo proton magnetic resonance spectroscopy. Longitudinal data were obtained from 70 infants ( 40 boys and 30 girls). In the neonatal period girls are more adipose in relation to body size than boys. At follow-up (median age 63 days), girls remained significantly more adipose. The greater relative adiposity that characterises girls is explained by more subcutaneous adipose tissue and this becomes increasingly apparent by follow-up. No significant sex differences were seen in IHCL. Sex-specific differences in infant adipose tissue distribution are in keeping with those described in later life, and suggest that sexual dimorphism in adiposity is established in early infancy.

International Journal of Obesity (2015) 39, 629-632; doi:10.1038/ijo.2015.4

\section{INTRODUCTION}

Sexual dimorphism in adipose tissue distribution and intrahepatocellular lipid (IHCL) are well described in adults. ${ }^{1,2}$ Adipose tissue distribution, specifically the accumulation of internal abdominal (IA) (or visceral) adipose tissue is strongly associated with cardiovascular and metabolic disease in adults ${ }^{3}$ (especially adult men $^{4}$ ) and children. ${ }^{5}$ The age at which sex differences in the distribution of adiposity begin to manifest remains unclear. Sex differences are established in adolescent, ${ }^{6}$ pre-adolescent $^{7}$ and pre-school children, ${ }^{8}$ implicating early childhood or infancy as the period of divergence, although there is a paucity of data describing adipose tissue distribution early in life. Here, we describe the longitudinal changes in directly measured adiposity and hepatic lipid that occur between birth and 2-3 months in healthy term babies in relation to infant sex.

\section{METHODS}

The results of this study represent secondary analyses of two previously described cohorts (cohort one recruited in November 1999-October 2001 at the Hammersmith Hospital; cohort two recruited in March 2010-May 2012 at Chelsea and Westminster Hospital, both in London, UK) recruited to examine the association between method of feeding and infant adiposity. ${ }^{9}$ Participants were healthy, full-term, appropriate weight for gestational age infants that underwent longitudinal measurements at two time points, baseline (shortly after birth) and follow-up (6-12 weeks). Infants of diabetic mothers and smokers were excluded. Maternal pre-pregnancy body mass index (BMI) was determined from prepregnancy weight obtained by maternal recall and maternal height measured at pregnancy booking. Data from both cohorts are presented together. The study was approved by the National Research Ethics Committee (10/H0713/5).
Anthropometric measures and magnetic resonance investigations were performed with infants in natural sleep, as previously described., ${ }^{9,10}$ Whole-body magnetic resonance images (MRIs) were acquired on a Phillips (Amsterdam, Netherlands) 1.5 Tesla system using a $\mathrm{T}_{1}$-weighted rapid-spin-echo sequence (repetition time of $500 \mathrm{~ms}$, echo time of $17 \mathrm{~ms}$, echo train length of 3) using a $\mathrm{Q}$ body coil. The slice thickness was $5 \mathrm{~mm}$ and interslice difference was $5 \mathrm{~mm}$. Voxel size was $0.31 \times 0.31 \times 0.31 \mathrm{~cm}$. Scanning time was $\sim 15 \mathrm{~min}$. Analysis of all magnetic resonance images was undertaken independently of the investigators and blind to participant identity and sex by VardisGroup, (London, UK, www.vardisgroup. com), using an image segmentation program (SliceOmatic, Tomovision, Montreal, Canada). Total adipose tissue volume was calculated as the sum of six individually quantified adipose tissue compartments (IA, internal non-abdominal, deep subcutaneous abdominal, deep subcutaneous non-abdominal, superficial subcutaneous abdominal, superficial subcutaneous non-abdominal) as previously described, ${ }^{9}$ Supplementary Figure 1. We calculated the ratio IA to subcutaneous abdominal, where SCA comprised the sum of the superficial subcutaneous abdominal and deep subcutaneous abdominal compartments. In adults, the ratio IA/ SCA correlates more strongly with cardiometabolic risk than the IA compartment alone. ${ }^{11}$

IHCL content was quantified as previously described. ${ }^{9}$ Briefly, proton magnetic resonance spectra were acquired at $1.5 \mathrm{~T}$ from the right lobe of the liver using a point-resolved spectroscopy sequence, repetition time $1500 \mathrm{~ms}$, echo time $135 \mathrm{~ms}$, without water saturation and with 128 signal averages. Spectra were analyzed in the time domain using the AMARES algorithm included in the MRUI software package (http://sermn02.uab.es/ mrui/mrui_download/) by a single investigator (ELT) blinded to infant identity and sex. Peak areas for all resonances were obtained and lipid resonances quantified with reference to water resonance, after correcting for $T_{1}$ and $T_{2}$. Hepatic water, known to

\footnotetext{
${ }^{1}$ Section of Neonatal Medicine, Chelsea and Westminster Hospital Campus, Imperial College London, London, UK; ${ }^{2}$ Robert Steiner MRI Unit, Hammersmith Campus, Imperial College London, London, UK; ${ }^{3}$ Radiology Department, St Mary's Hospital, London, UK and ${ }^{4}$ Department of Life Sciences, University of Westminster, London, UK. Correspondence: Professor N Modi, Section of Neonatal Medicine, Chelsea and Westminster Hospital Campus, Imperial College London, 4th Floor, Lift Bank D, Chelsea and Westminster Hospital, 369 Fulham Road, London SW10 9NH, UK.

E-mail: n.modi@imperial.ac.uk

Received 5 October 2014; revised 1 December 2014; accepted 3 December 2014; accepted article preview online 23 January 2015 ; advance online publication, 17 February 2015
} 
be relatively constant, ${ }^{12}$ was used as an internal standard. The results are presented as the ratio $\mathrm{IHCL} \mathrm{CH}_{2} /$ water.

\section{Statistical analyses}

Analyses were performed using SPSS version 20 (IBM Corporation, Armonk, NY, USA). Statistical significance was defined as $P<0.05$. Where data were not normally distributed $(P<0.05$ from the Shapiro-Wilk test), a natural log transformation was undertaken. Where data remained non-normal in distribution, non-parametric tests were used.

We compared girls and boys using multivariable regression to examine total adipose tissue, each adipose tissue depot and $\mathrm{IHCL}$, with infant weight as a covariate to adjust for body size. The ratio IA/SCA is a measure of metabolic load; to compare boys and girls, the optimal index for infancy ${ }^{13}\left(I A / S C A^{0.6}\right)$ was calculated. This index has not to our knowledge been correlated with metabolic variables in infancy. This index is correlated with body weight at follow-up ( $P<0.05$; Spearman's correlation), therefore multivariable regression was used with infant weight as a covariate. As ethnicity and maternal BMI are associated with adiposity in infancy, ${ }^{14,15}$ sensitivity analyses were undertaken after exclusion of non-Caucasian infants and with adjustment for maternal BMI. No significant association has been detected between method of infant feeding and directly measured adipose tissue, ${ }^{9}$ therefore the feeding group was not included in the multivariable adjustment.

\section{RESULTS}

Longitudinal adiposity data were acquired from 70 infants (40 boys and 30 girls); these data have been previously described. ${ }^{9}$ Mean (SD) gestation, birth weight and birth weight SDS scores were $39.8(1.4)$ weeks, $3.441(0.397) \mathrm{kg}$ and $-0.12(0.79)$ for boys and 40.0 (1.2) weeks, $3.350(0.404) \mathrm{kg}$ and -0.02 (0.85) for girls. Mean (s.d.) maternal pre-pregnancy maternal BMI was 22.8 (2.4) $\mathrm{kg} \mathrm{m}^{-2}$ for boys and 24.3 (5.3) $\mathrm{kg} \mathrm{m}^{-2}$ for girls. Demographic data and unadjusted adiposity data are presented by infant sex in Table 1.

Adjusted analyses are shown in Table 2. After adjusting for body size, girls had significantly more total and superficial subcutaneous abdominal adipose tissue than boys in early infancy (median age
13 days). At follow-up (median age 63 days), all adjusted adipose depots were larger in girls; these differences reached statistical significance for internal non-abdominal, deep subcutaneous abdominal, superficial subcutaneous abdominal and superficial subcutaneous non-abdominal adipose tissue depots. Sensitivity analyses with adjustment for maternal BMI and after exclusion of non-Caucasian infants did not alter these findings (Supplementary Table 1). No significant difference was detected in the ratio IA: SCA ${ }^{0.6}$ between boys and girls $(P=0.38$ at baseline; $P=0.43$ at follow-up). No sex-specific differences in $\mathrm{IHCL}$ were detectable at baseline or follow-up.

\section{DISCUSSION}

We confirm, in this longitudinal cohort of healthy term babies, that sex-specific differences in total adiposity are present from shortly after birth. These differences become more pronounced by 2-3 months by which time a difference in adipose tissue distribution, characterised by higher subcutaneous adipose tissue volumes in girls, is detectable. The greater relative adiposity in girls compared with boys is in keeping with recognised sex differences, ${ }^{16,17}$ but to our best knowledge a sex difference in adipose tissue distribution in early infancy has not been described previously in longitudinal measurements. The strengths of this study include the use of an established gold standard method, whole-body $\mathrm{MRI}^{18}$ to quantify adipose tissue distribution in combination with blinded image analysis. Important limitations include the secondary nature of this study and that initial measurements were taken at a median of 13 days, so we are unable to comment on differences present at birth.

Sex-specific differences in adult adipose tissue distribution were first recognised by Vague et al.; ${ }^{1}$ these differences, namely more IA adipose tissue and less subcutaneous adipose tissue in men, are implicated in the higher cardiovascular risk seen in men compared with pre-menopausal women. ${ }^{4}$ There are limited data on the ontogeny of sex-specific differences in adipose tissue distribution. We have previously noted small differences in newborns with greater total adipose tissue, and larger abdominal and nonabdominal compartments in girls. ${ }^{15}$ By the age of 5 years, boys have more IA adipose tissue than girls but a similar amount of SCA adipose tissue, ${ }^{8}$ and by puberty, differences in keeping with those

Table 1. Anthropometric data, adipose tissue compartment volumes and $\mathrm{IHCL}$ at baseline and follow-up by infant sex

\begin{tabular}{|c|c|c|c|c|}
\hline & \multicolumn{2}{|c|}{ Baseline } & \multicolumn{2}{|c|}{ Follow-up } \\
\hline & Boys & Girls & Boys & Girls \\
\hline$n$ & 40 & 30 & 40 & 30 \\
\hline Age (days) & $13[7-20]$ & $13[5-18]$ & $64[54-70]$ & $62[56-71]$ \\
\hline Weight $(\mathrm{kg})$ & $3.637(0.489)$ & $3.546(0.518)$ & $5.492(0.687)$ & $5.219(0.533)$ \\
\hline Weight SDS ${ }^{a}$ & $-0.25(0.94)$ & $-0.17(0.78)$ & $-0.12(0.99)$ & $0.13(0.55)$ \\
\hline$n$ & 40 & 29 & 39 & 30 \\
\hline Total AT (I) & $0.709[0.608-0.932]$ & $0.730[0.626-0.906]$ & $1.548[1.278-1.801]$ & $1.485[1.345-1.817]$ \\
\hline Superficial subcutaneous abdominal AT (I) & $0.098[0.075-0.122]$ & $0.104[0.087-0.0139]$ & $0.257[0.198-0.316]$ & $0.258[0.223-0.326]$ \\
\hline Superficial subcutaneous non-abdominal AT (I) & $0.512[0.436-0.692]$ & $0.515[0.461-0.653]$ & $1.124[0.935-1.270]$ & $1.085[0.927-1.263]$ \\
\hline Deep subcutaneous abdominal AT & $0.015[0.010-0.021]$ & $0.017[0.011-0.022]$ & $0.037[0.028-0.046]$ & $0.044[0.031-0.053]$ \\
\hline Deep subcutaneous non-abdominal AT (I) & $0.012[0.010-0.022]$ & $0.013[0.010-0.016]$ & $0.020[0.016-0.023]$ & $0.020[0.015-0.024]$ \\
\hline Internal abdominal AT (I) & $0.017[0.013-0.022]$ & $0.017[0.012-0.027]$ & $0.030[0.022-0.038]$ & $0.030[0.023-0.042]$ \\
\hline Total internal AT (I) & $0.071[0.055-0.091]$ & $0.069[0.060-0.097]$ & $0.118[0.096-0.148]$ & $0.130[0.110-0.156]$ \\
\hline $\mathrm{IA} / \mathrm{SCA}^{\mathrm{a}}$ & $0.16[0.12-0.20]$ & $0.14[0.11-0.16]$ & $0.10[0.08-0.15]$ & $0.10[0.08-0.13]$ \\
\hline IA/SCA ${ }^{0.6}$ & $0.067(0.021)$ & $0.062(0.022)$ & $0.069(0.024)$ & $0.067(0.025)$ \\
\hline$n$ & 31 & 23 & 31 & 23 \\
\hline $\mathrm{IHCL} \mathrm{L}^{\mathrm{b}}$ & $0.656[0.425-1.965]$ & $1.142[0.667-1.644]$ & 1.818 [1.397-2.168] & $2.123[1.278-3.229]$ \\
\hline
\end{tabular}

Abbreviations: AT, adipose tissue; IA, internal abdominal; IHCL, intrahepatocellular lipid; SCA, subcutaneous abdominal. Values are median and [interquartile range] or mean (s.d.) and units are as specified except ${ }^{a}$ that has no units and ${ }^{b}$ that is ratio $\mathrm{CH}_{2} /$ water. 
Table 2. Mean difference in adiposity (I) and $\mathrm{IHCL}$ (ratio $\mathrm{CH}_{2}: \mathrm{H}_{2} \mathrm{O}$ ) at follow-up, boys compared with girls (adjusted for weight at imaging)

\begin{tabular}{|c|c|c|c|c|c|c|}
\hline & \multicolumn{3}{|c|}{ Baseline } & \multicolumn{3}{|c|}{ Follow-up } \\
\hline & $\mathrm{R}^{2}$ & Adjusted mean difference & $P$ & $R^{2}$ & Adjusted mean difference & $P$ \\
\hline Total AT & 0.58 & $-0.075(-0.154,0.001)$ & 0.05 & 0.63 & $-0.193(-0.312,-0.074)$ & 0.002 \\
\hline Superficial subcutaneous abdominal AT & 0.48 & $-0.018(-0.033,-0.002)$ & 0.02 & 0.44 & $-0.039(-0.070,-0.007)$ & 0.02 \\
\hline Superficial subcutaneous non-abdominal AT & 0.59 & $-0.046(-0.100,0.008)$ & 0.09 & 0.64 & $-0.124(-0.205,-0.043)$ & 0.003 \\
\hline Internal non-abdominal AT & 0.33 & $-0.007(-0.015,0.001)$ & 0.07 & 0.40 & $-0.019(-0.032,-0.005)$ & 0.007 \\
\hline Ratio $(\mathrm{IA} / \mathrm{SCA})^{0.6}$ & 0.02 & $0.01(-0.01,0.02)$ & 0.37 & 0.07 & $0.01(-0.01,0.02)$ & 0.38 \\
\hline$n$ & & 54 & & & 54 & \\
\hline $\mathrm{IHCL}$ & $0.02^{*}$ & $-6.4 \%(-39.7 \%, 45.2 \%)^{*}$ & $0.76^{* *}$ & $0.04^{*}$ & $-31.3 \%(-60.7 \%, 20.1 \%)^{*}$ & $0.18^{* *}$ \\
\hline
\end{tabular}

described in adults are established. ${ }^{7}$ Our observations suggest that sexual divergence in adipose tissue distribution occurs in early infancy. Adipose tissue is considered an important energy reserve in the weaning period, ${ }^{19}$ and the greater relative adiposity of baby girls may contribute to the survival advantage they manifest in early life. ${ }^{20}$ Sex-specific differences in IHCL are described in adults, ${ }^{2}$ but we find no evidence for such a difference in infancy. We have previously commented on the substantial increase in IHCL during early infancy suggesting that the high content is not of pathological relevance as in older age groups. $^{8}$

Sex-related adiposity differences have been attributed to sex hormones; testosterone mediates deposition of adipose tissue in abdominal regions and oestrogen in gluteo-femoral regions. ${ }^{21}$ Androgen receptors are more densely expressed in visceral than in subcutaneous adipose tissue. ${ }^{22}$ There is surge shortly after birth in luteinising hormone (LH), follicle-stimulating hormone (FSH) and sex hormones, although levels are generally low in childhood. This has been termed a 'minipuberty of early infancy'; ${ }^{23}$ in boys FSH, LH and testosterone concentrations increase during the first week before decreasing by about 6 months, whereas in girls FSH, LH and oestrogen increase shortly after birth and remain raised until $2-3$ years. ${ }^{23}$ The gender-related divergence in adipose tissue distribution we observed may be mediated by these hormonal fluctuations.

Adipose tissue quantity and distribution are important determinants of health. Data presented here indicate that the sexspecific divergence seen in adults develops during early infancy. If confirmed this supports the importance of the infant period in mediating trajectories of adipose tissue development.

\section{CONFLICT OF INTEREST}

CG received support from Pfizer Nutrition to attend an educational conference. In the last 5 years NM has received consultancy fees from Ferring Pharmaceuticals, speaker honorarium for an educational meeting funded by Nestle International in which they had no organisational involvement and grants from the Medical Research Council, National Institute of Heath Research, Westminster Children's Trust Fund, Child Growth Foundation, HCA International, Bliss, British Heart Foundation, and Department of Health. The remaining authors declare no conflict of interest.

\section{ACKNOWLEDGEMENTS}

We are grateful to the many parents that consented to their baby's participation in our studies and the funding bodies that made this work possible. Salary support for
CG provided by Chelsea and Westminster Hospital Charity; salary support for KML provided by Action Medical Research; ELT, JDB and GD are supported by the Medical Research Council.

\section{REFERENCES}

1 Vague J. The degree of masculine differentiation of obesities: a factor determining predisposition to diabetes, atherosclerosis, gout, and uric calculous disease. Am J Clin Nutr 1956; 4: 20-34.

2 Thomas EL, Parkinson JR, Frost GS, Goldstone AP, Dore CJ, McCarthy JP et al. The missing risk: MRI and MRS phenotyping of abdominal adiposity and ectopic fat. Obesity (Silver Spring) 2012; 20: 76-87.

3 Despres JP, Lemieux I, Bergeron J, Pibarot P, Mathieu P, Larose E et al. Abdominal obesity and the metabolic syndrome: contribution to global cardiometabolic risk. Arterioscler Thromb Vasc Biol 2008; 28: 1039-1049.

4 Lemieux S, Despres JP, Moorjani S, Nadeau A, Theriault G, Prud'homme D et al. Are gender differences in cardiovascular disease risk factors explained by the level of visceral adipose tissue? Diabetologia 1994; 37: 757-764.

5 Owens S, Gutin B, Ferguson M, Allison J, Karp W, Le NA. Visceral adipose tissue and cardiovascular risk factors in obese children. J Pediatr 1998; 133: 41-45.

6 Shen W, Punyanitya M, Silva AM, Chen J, Gallagher D, Sardinha LB et al. Sexual dimorphism of adipose tissue distribution across the lifespan: a crosssectional whole-body magnetic resonance imaging study. Nutr Metab (Lond) 2009; 6: 17.

7 He Q, Horlick M, Thornton J, Wang J, Pierson Jr RN, Heshka S et al. Sex and race differences in fat distribution among Asian, African-American, and Caucasian prepubertal children. J Clin Endocrinol Metab 2002; 87: 2164-2170.

8 Karlsson AK, Kullberg J, Stokland E, Allvin K, Gronowitz E, Svensson PA et al. Measurements of total and regional body composition in preschool children: a comparison of MRI, DXA, and anthropometric data. Obesity (Silver Spring) 2013; 21: 1018-1024.

9 Gale C, Thomas EL, Jeffries S, Durighel G, Logan KM, Parkinson JR et al. Adiposity and hepatic lipid in healthy full-term, breastfed, and formula-fed human infants: a prospective short-term longitudinal cohort study. Am J Clin Nutr 2014; 99: 1034-1040.

10 Gale C, Jeffries S, Logan KM, Chappell KE, Uthaya SN, Modi N. Avoiding sedation in research MRI and spectroscopy in infants: our approach, success rate and prevalence of incidental findings. Arch Dis Child Fetal Neonatal Ed 2012; 98: F267-F268.

11 Kaess BM, Pedley A, Massaro JM, Murabito J, Hoffmann U, Fox CS. The ratio of visceral to subcutaneous fat, a metric of body fat distribution, is a unique correlate of cardiometabolic risk. Diabetologia 2012; 55: 2622-2630.

12 Emery JL, Finch E. The fat and water content of the left and right liver before and after birth. Arch Dis Child 1954; 29: 242-247.

13 Gale C, Santhakumaran S, Wells JC, Modi N. Adjustment of directly measured adipose tissue volume in infants. Int J Obes (Lond) 2014; 38: 995-999. 
14 Modi N, Thomas EL, Uthaya SN, Umranikar S, Bell JD, Yajnik C. Whole body magnetic resonance imaging of healthy newborn infants demonstrates increased central adiposity in Asian Indians. Pediatr Res 2009; 65: 584-587.

15 Modi N, Murgasova D, Ruager-Martin R, Thomas EL, Hyde MJ, Gale C et al. The influence of maternal body mass index on infant adiposity and hepatic lipid content. Pediatr Res 2011; 70: 287-291.

16 Fomon SJ, Haschke F, Ziegler EE, Nelson SE. Body composition of reference children from birth to age 10 years. Am J Clin Nutr 1982; 35: 1169-1175.

17 Butte NF, Hopkinson JM, Wong WW, Smith EO, Ellis KJ. Body composition during the first 2 years of life: an updated reference. Pediatr Res 2000; 47: 578-585.

18 Cornier MA, Despres JP, Davis N, Grossniklaus DA, Klein S, Lamarche B et al. Assessing adiposity: a scientific statement from the American Heart Association. Circulation 2011; 124: 1996-2019.

19 Kuzawa CW. Adipose tissue in human infancy and childhood: an evolutionary perspective. Am J Phys Anthropol 1998; 27: 177-209.

20 Mage DT, Donner M. Female resistance to hypoxia: does it explain the sex difference in mortality rates? J Womens Health 2006; 15: 786-794.
21 Norgan NG. The beneficial effects of body fat and adipose tissue in humans Int J Obes Relat Metab Disord 1997; 21: 738-746.

22 Rosenbaum M, Leibel RL. Clinical review 107: Role of gonadal steroids in the sexual dimorphisms in body composition and circulating concentrations of leptin. J Clin Endocrinol Metab 1999; 84: 1784-1789.

23 Grumbach MM. A window of opportunity: the diagnosis of gonadotropin deficiency in the male infant. J Clin Endocrinol Metab 2005; 90: 3122-3127.

\section{cc) (i)}

This work is licensed under a Creative Commons Attribution 4.0 International License. The images or other third party material in this article are included in the article's Creative Commons license, unless indicated otherwise in the credit line; if the material is not included under the Creative Commons license, users will need to obtain permission from the license holder to reproduce the material. To view a copy of this license, visit http://creativecommons.org/licenses/ by/4.0/

Supplementary Information accompanies this paper on International Journal of Obesity website (http://www.nature.com/ijo) 